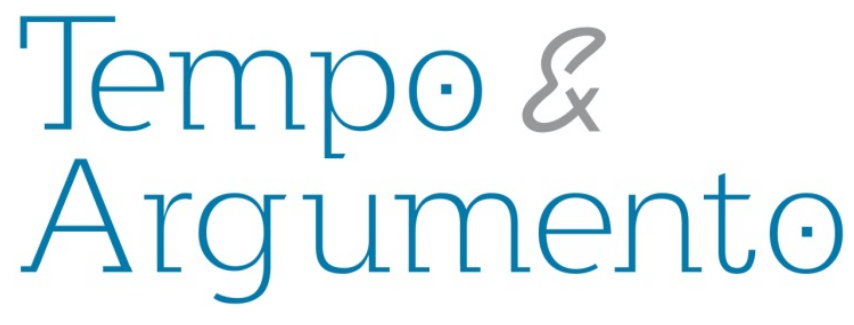

\title{
De tablet para tablet - novas ferramentas para a pesquisa e o ensino da história das culturas cuneiformes na era digital ${ }^{1}$
}

\begin{abstract}
Resumo
A chamada era digital tem possibilitado formas de diálogo e interação que outrora sequer poderíamos imaginar; sem dúvida, uma nova realidade para várias subáreas da História Antiga. Ampliaram-se as possibilidades para a pesquisa e o ensino da história das culturas cuneiformes, principalmente em países com pouca tradição acadêmica nesta área específica, como é o caso do Brasil. Afastados das grandes universidades e principais centros de estudo, professores e estudantes desafiam limitações financeiras, impedimentos burocráticos e barreiras linguísticas para ter acesso ao que de mais atual vem sendo produzido neste campo, no qual a sistematização digital das informações se tem constituído em ferramenta decisiva para auxiliar os interessados na temática. Apesar disso, dos 74\% deprofessores brasileiros de História Antiga que pesquisam ou Grécia ou Roma, apenas 2,17\% são assiriólogos. O objetivo deste artigo é discutir algumas destas questões.
\end{abstract}

Palavras-chave: Cultura Cuneiforme - História; História Antiga - estudo e ensino; Internet na educação.

\author{
Dominique Vieira Coelho dos Santos \\ Doutor em História pela Universidade \\ Federal de Goiás. Professor de História \\ Antiga da Universidade Regional de \\ Blumenau - FURB. Coordenador do \\ Laboratório Blumenauense de Estudos \\ Antigos e Medievais. \\ Brasil \\ dvcsantos@furb.br
}

\section{Para citar este artigo: \\ SANTOS, Dominique Vieira Coelho dos. De tablet para tablet - novas ferramentas para a pesquisa e o ensino da história das culturas cuneiformes na era digital. Revista Tempo e Argumento, Florianópolis, v. 6, n. 12, p. 212 - 241, mai./ago. 2014.}

DOI: $10.5965 / 2175180306122014212$

http://dx.doi.org/10.5965/2175180306122014212

\footnotetext{
${ }^{1} \mathrm{O}$ artigo em questão foi possível graças ao projeto de pesquisa 667/2012, intitulado: Culturas, fronteiras e identidades: repensando a Antiguidade entre o Mediterrâneo e o Mar da Irlanda, subsidiado pela Propex/FURB
} 


\title{
From tablet to tablet- new tools for researching and teaching the history of cuneiform cultures in the digital era
}

\begin{abstract}
The so-called digital age has allowed forms of dialogue and interactions that once could not even exist, definitely, a new reality for several sub-areas of Ancient History. The possibilities for researching and teaching the history of cuneiform cultures have been expanded, especially in countries with a weak academic tradition in this particular historiographical area, as is the case of Brazil. Away from main universities and research centers, professors and students challenge financial restrictions, bureaucratic impediments and language barriers to have access to the forefront of the knowledge in this field and digital systematization of information has acted as a decisive tool to assist the ones interested in the subject. Although, 74\% of Brazilian Ancient History professors research or Greece or Rome, while just 2:17\% are Assyriologists. This article aim is to address some of these issues.
\end{abstract}

Keywords: Cuneiform Culture - History; Ancient History - study and teaching; Internet in education.

Ainda que nem todos tenham acesso garantido e oportunidades semelhantes, a chamada era digital é uma realidade. Uma rápida consulta a qualquer tipo de noticiário com informações corriqueiras basta para que estejamos diante de uma incrível variedade de termos que surgiram no universo da linguagem pós-internet: website,blog, rede social, hipertexto, hipermídia, multimídia, multitarefa, multiconectado, armazenamento nas nuvens, e assim por diante. O vocabulário relacionado com a internet e o uso de 
computadores, tablets e smartphones é tão amplo que há vários dicionários específicos para tratar do tema (SAWAYA, 1999; DAINTITH e WRIGHT, 2008). Ainda há pouco tempo, alguns docentes apresentavam preocupações sobre se os trabalhos solicitados para suas disciplinas poderiam ou não ser digitalizados; se consultas ao computador deveriam ou não ser aceitas. Hoje, uma geração inteira dos alunos que chegaram recentemente à universidade já chega alfabetizada, tendo palavras como "escanear", "ripar", “digitalizar", e outras, como parte da linguagem cotidiana.Aquelas preocupações, portanto, perderam sentido. Os estudantes têm acesso a mais de uma tela e as conexões estão cada vez mais velozes; um mundo desconectado parece sequer possível (LUCCHESI, 2012; 2013).

Estes questionamentos não demorariam a atingir a galáxia de Heródoto. Pesquisas mais recentes têm demonstrado uma enorme preocupação por parte dos historiadores com relação a este fenômeno: Será que estas novas tecnologias vão alterar a natureza e as práticas características da disciplina? Ou elas são apenas recursos? A internet tem mesmo democratizado o acesso à produção historiográfica ou o número de limites e restrições é grande demais, a ponto de impedir um verdadeiro open access? A era digital tem permitido um maior diálogo entre a academia, as instituições escolares e o que tem sido denominado public history? Tem-se alterado o ensino de História diante destas perspectivas? O livro digital vai coexistir com o codex? Plataformas e projetos elaborados por grandes corporações como as que existem hoje, caso do Google, por exemplo, representam perigo de monopólio do conhecimento? Como tratar a questão da autoria coletiva na era digital?

Estas são apenas algumas das questões do tempo presente no que diz respeito ao tema (DARNTON, 2010; DANIEL, 2012; TAVARES, 2012).

Estas inquietações, de uma maneira geral, já fazem parte da agenda de discussões dos historiadores; não seria diferente entre os que se ocupam com a chamada História Antiga, em qualquer uma de suas divisões ou especialidades. Vários profissionais têm trabalhado neste novo campo e os resultados começam a aparecer. 0 classicadigitalia.uc.pt, da Universidade de Coimbra, e o www.digitalclassicist.org, do King's College London, são exemplos de projetos que criaram uma rede internacional de 
comunicação na área de estudos clássicos. No Brasil, também há vários grupos e laboratórios de pesquisa dedicados exclusivamente à área de História Antiga, que funcionam de forma parcial ou total online. Uma sitegrafia recomendada por especialistas pode ser encontrada, por exemplo, tanto no site da Sociedade Brasileira de Estudos Clássicos (SBEC) (classica.org.br), quanto no do Grupo de Trabalho em História Antiga (gtantiga.com) (GTHA), da Associação Nacional de História (Anpuh). Já existem pesquisas mais recentes que se dedicaram a pensar de forma mais detalhada esta temática, como as propostas da historiadora Juliana Bastos Marques sobre a construção das narrativas acerca da história romana na Wikipédia (MARQUES, 2013).

Da mesma forma, ampliaram-se as possibilidades para a pesquisa e o ensino da história das culturas cuneiformes, o que é muito importante, principalmente em países com pouca tradição acadêmica nesta área historiográfica específica, como é o caso do Brasil. Afastados das grandes universidades e principais centros de estudo, professores e estudantes desafiam limitações financeiras, impedimentos burocráticos e barreiras linguísticas para ter acesso ao que de mais atual vem sendo produzido neste campo específico do saber e à sistematização digital das informações, que se tem constituído em ferramenta decisiva para auxiliar os interessados na temática. Ou seja, esta nova realidade não pode mais ser ignorada; precisa fazer parte do cotidiano das pesquisas e do ensino da história das culturas cuneiformes e deve servir para aumentar o número de estudos na área. Afinal, para os pesquisadores brasileiros da área de História Antiga, a era digital representou um divisor de águas, pois encurtou distâncias, facilitou a comunicação, permitiu o aumento de networks de pesquisadores e, principalmente, diminuiu, ressignificou e redimensionou a necessidade de idas ao exterior, sobretudo aquelas destinadas à busca de material impresso. Estas possibilidades também devem impulsionar a assiriologia brasileira. 


\section{Algumas considerações sobre a pesquisa e o ensino de história antiga no Brasil e o estudo das culturas cuneiformes}

A área de História Antiga cresceu muito no Brasil nas últimas décadas, tanto em quantidade quanto em qualidade. Para Pedro Paulo A. Funari, esta ampliação pode ser percebida tanto por meio do aumento de textos sobre História Antiga, escritos por pesquisadores brasileiros, quanto de traduções de documentos históricos (FUNARI, 2005). Pensamento semelhante tem Carlos Eduardo da Costa Campos. Para ele, "os núcleos e grupos de pesquisa, os eventos para debates e o crescimento da massa crítica são indicadores que refletem o estágio de desenvolvimento da área" (CAMPOS, 2012). Já Maria Regina Candido explica que o uso da internet, como um facilitador de pesquisa, e a divulgação de temáticas relacionadas com a Antiguidade no cinema e em outras mídias colaboraram para este crescimento (CANDIDO, 2009). Outro autor que escreveu sobre este crescimento é o historiador Fábio Faversani. Segundo ele, a produção na área de História Antiga é muito superior à produzida algumas décadas atrás. O número de livros publicados, por exemplo, é muito maior, como também o é o de artigos, periódicos, dissertações e teses produzidas na área (FAVERSANI, 2009). Outro indício apontado pelos pesquisadores, facilmente observável por quem trabalha na área, é o aumento significativo do número de cursos de história que já tem em seu quadro de professores especialistas nos estudos sobre antiguidade, ou seja, docentes que pesquisam de forma permanente temáticas referentes a este período histórico específico e que orientam estudantes desde a graduação até o doutorado nesta área. São várias as pesquisas recentes que têm procurado apresentar resumos deste quadro (CARVALHO e FUNARI, 2007; GARRAFONI e FUNARI, 2010; SILVA, 2011).

O já mencionado Grupo de Trabalho em História Antiga (GTHA), da Associação Nacional de História (Anpuh), disponibilizou em sua página na internet, a partir do link "História Antiga em seu Estado", uma classificação detalhada dos docentes que pesquisam e ensinam esta disciplina em alguma instituição de ensino superior no Brasil. Foram registrados, segundo se lê na própria página do grupo, docentes com “vínculos permanentes em cada instituição, lotados nos departamentos de história e concursados na disciplina de História Antiga ou, em alguns casos, História Antiga e Medieval, situação 
que era comum no passado" (gtantiga.com/estados.htm). Todos os dados foram distribuídos em forma de mapa do Brasil interativo; com um clique sobre qualquer estado, é possível verificar os docentes responsáveis por lecionar História Antiga. Cada nome é acompanhado por duas informações: primeiramente, a instituição na qual atua; a seguir, algo muito importante, um link para o Currículo Lattes do pesquisador (a), disponível na Plataforma Lattes (lattes.cnpq.br).

A partir de uma pesquisa destes dados e de uma análise dos currículos de todos os docentes informados na página do GTHA, foi possível observar algumas questões bastante relevantes sobre a área de História Antiga no Brasil, como, por exemplo, o quanto se tem publicado e quais as temáticas específicas mais estudadas. Os docentes de História Antiga, representados no mapa do GTHA, originaram 2.022 "artigos completos publicados em periódicos"; 462 "livros publicados/organizados ou edições" e 1.029 "capítulos de livros publicados". De igual modo, verificando as "orientações e supervisões concluídas", percebemos que orientaram 636 trabalhos de iniciação científica; 802 trabalhos de conclusão de curso; 195 monografias de especialização; 400 dissertações de mestrado e 96 teses de doutorado ${ }^{2}$. Ou seja, uma quantidade significativa de intervenções.Sem dúvida, um quadro bastante diferente de um passado não muito distante.

No entanto, parece que a assiriologia não acompanhou este crescimento, pois as pesquisas nesta área não se desenvolveram como as demais, que receberam muito mais

\footnotetext{
${ }^{2}$ A metodologia aplicada resultou na quantificação do número total de publicações/orientações pelos docentes de História Antiga nas categorias mencionadas.Isto significa que nem todos os itens listados como publicações/orientações têm como objeto temas relacionados exclusivamente com esta disciplina; afinal, estes docentes também emprestaram seu conhecimento, colaborando para gerar publicações interdisciplinares e coletivas em outras áreas do conhecimento histórico. Evidentemente, uma pesquisa mais demorada e cuidadosa poderia quantificar apenas os artigos e orientações empreendidos na área de História Antiga strictu sensu.Apesar disso, este fator não representa um prejuízo para o argumento principal de crescimento da área. Se, por um lado, a adoção de tal procedimento nos obrigaa eliminar alguns artigos como não sendo de História Antiga, o que faria seu número diminuir, por outro, bastaria considerar as publicações e orientações de professores substitutos, de discentes de graduação, mestrado e doutorado, e daqueles que não são da área de História -, e por isso geralmente não filiados à Anpuh -, mas que estudam temáticas relacionadas com a Antiguidade, para que o número final total atual receba acréscimo, aumentando em várias vezes. De igual modo, as considerações sobre o que tem sido realizado na área de assiriologia também não são afetadas, principalmente porque estes estudantes, em sua quase totalidade, pesquisam outras temáticas diferentes da que nos interessa. $O$ mesmo vale para os professores de outras áreas do conhecimento (letras clássicas, arqueologia, filosofia, etc.); grande parte é associada à SBEC, e se dedica, portanto, aos estudos clássicos.
} 
atenção dos docentes ocupados com os estudos sobre a Antiguidade. De todas as publicações mencionadas, as diretamente relacionadas com a história das culturas cuneiformes não passam de algumas poucas dezenas. Ainda assim, para obter este número, é preciso levar em consideração artigos publicados por professores que são especialistas em outras temáticas da antiguidade, mas que, por um motivo ou outro, escreveram algo relacionado com a assiriologia. São exemplos assim os historiadores Dominique Santos, da Universidade de Blumenau, e Fábio Vergara Cerqueira, da Universidade Federal de Pelotas. O primeiro, apesar de pesquisar História da Irlanda Antiga, atuando principalmente nos temas dos intercâmbios e conexões entre a Irlanda e a Bretanha romana, Cristianização da Irlanda e Tradição Hiberno-Latina, publicou um artigo sobre as representações do espaço da cidade na epopeia de Gilgamesh (SANTOS, CONTADOR e CRESCÊNCIO, 2012). O segundo, cujo principal tema de investigação são a música e a iconografia na antiguidade clássica, sobretudo os instrumentos musicais na vida diária da Atenas tardo-arcaica e clássica- seu tema de doutoramento -, nos últimos anos se tem dedicado a áreas de memória social, patrimônio cultural e gestão museológica. Para compreender a difusão de tradições musicais e organológicas, escreveu um capítulo de livro no qual precisou recuar até a cidade de Ur para perceber como a música da Mesopotâmia foi importante para a formação da grega (CERQUEIRA, 2013).

O mapeamento realizado pelo GTHA sistematizou 92 professores de História Antiga. Dentre estes, 36 pesquisam a História de Roma, ou alguma temática relacionada; 32 têm como foco a Grécia Antiga; sete estão interessados no Egito Antigo; seis estudam Israel Antigo/Hebreus/Judaísmo; seis pesquisam temas que podemos classificar como relacionados com a antiguidade tardia, vinculados a regiões e povos que vão desde a África até a Península Ibérica; dois estudam a história das culturas cuneiformes; dois estudam celtas e um deles estuda a China Antiga. Vejamos o gráfico abaixo: 


\section{História Antiga no Brasil - Número de pesquisadores por área de interesse}

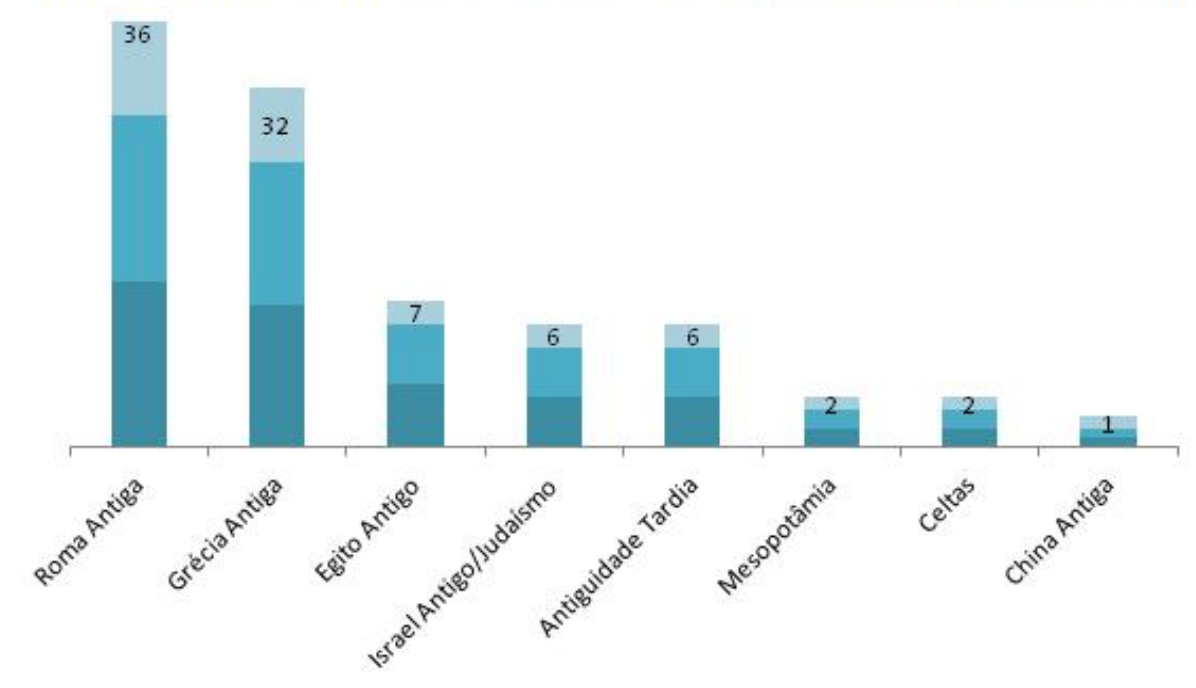

Fonte: dados obtidos por meio de pesquisa à página do GTHA

Como podemos observar, a grande maioria dos 92 professores brasileiros de História Antiga ou estuda Grécia ou estuda Roma. É até sintomático que o número de pesquisadores de Grécia (32) seja quase o mesmo que o de Roma (36). Ou seja, 39\% dos docentes estudam Roma, enquanto que 35\% estudam Grécia. Estas duas temáticas da História Antiga representam, juntas, um total de 68 docentes, incríveis $74 \%$ do total de pesquisadores da área. Apenas dois professores de História Antiga (2,17\% do total do mapa apresentado pela página do GTHA) são assiriólogos: Katia Maria Paim Pozzer, da Universidade Federal do Rio Grande do Sul (UFRGS), e Marcelo Rede, da Universidade de São Paulo (USP) 3 . Além dos dois, é importante mencionar ainda Carlos Henrique Barbosa Gonçalves, professor da Escola de Artes, Ciências e Humanidades da USP, pois ele tem empreendido pesquisas significativas sobre os saberes na antiguidade mesopotâmica; fez pós-doutorado no Institut für Orientalistik da Universidade de Viena; é filiado à International Association for Asysriology. Sua tese de livre docência, defendida na própria

\footnotetext{
${ }^{3}$ As porcentagens foram arredondadas para mais ou para menos, tendo como critério a maior proximidade de um número com apenas duas casas. Isto nos permitiu evitar números gigantes. Os dois professores dedicados à assiriologia no Brasil, por exemplo, representam exatos $2.1739130434782608 \%$ do total de docentes.
} 
USP em 2012, por exemplo, foi sobre os tablets matemáticos de Tell Harmal. Gonçalves tem publicado artigos sobre matemática na Mesopotâmia e também orientou/a quatro trabalhos na área (uma dissertação de mestrado e três trabalhos de conclusão de curso).

Alguns estudantes também têm trabalhado sobre temáticas da assiriologia, fazendo parte de projetos de iniciação científica, escrevendo trabalhos de conclusão de curso e também dissertações de mestrado. São os casos, por exemplo, de Gabriel Gróf, que fez mestrado sobre o gerenciamento de dados administrativos de Uruk, do IV milênio a. C., sob orientação de Marcelo Rede; Simone Silva da Silva, que estuda representações e significados de divindades nos relevos da sala do trono de Assurbanipal II (883-859 a. C.); Ricardo Silva Serres, que estudou a tecnologia de guerra nos relevos assírios; Cláudia Andrade da Silva, que estudou agrimensura neosumérica; Debora Marinho Correa, que estudou os relevos assírios no reinado de Assurbanipal; Bruno Barsante, que estudou os relevos de Senaqueribe; Paula Ledur, que estudou a iconografia assíria do reino de Assurbanipal; Jéssica Lima, que estudou a representação dos estrangeiros nos relevos assírios, e Laurence Würdig Gonçalves, que estudou textos sumérios e acádicos do acervo do Museu de Arqueologia e Etnologia da Universidade de São Paulo, todos sob orientação de Katia Pozzer.

De igual modo, há quem tenha feito pesquisas, seja vinculados aos departamentos de história ou a outras áreas do saber, que estabeleceram algum tipo de relação com a assiriologia, mesmo sem contar com a assistência direta de um especialista nesta área, capaz, por exemplo, de ler e traduzir algum idioma que faz uso do script cuneiforme. Antonio Celso Xavier de Oliveira, por exemplo, fez uma tese de doutorado em Arquitetura e Urbanismo pela USP, na qual analisou a urbanização na antiguidade, desde Uruk até a Villa Hadriana. Philippe Racy Takla tem experiência na área de arqueologia do Médio Oriente, com ênfase em arqueologia da Mesopotâmia durante o período assírio, e iniciou um doutorado sobre o tema, também na USP; no entanto, por algum motivo, interrompeu seus estudos em 2010. Gioseppina Pappacena estudou a influência religiosa da Mesopotamia sobre o povo hebreu, numa dissertação de mestrado em Ciência da Religião no Instituto Brasileiro de Educação, Cultura e Ciência. Maria Isabelle de Paula Souza também escreveu uma pela UFPR sobre o simbolismo aquático na Epopeia de 
Gilgamesh. Simone Aparecida Dupla faz mestrado na UEPG, estudando permanências e adaptações do culto de Inanna, de Uruk Antigo à época paleobabilônica (3100-1600 a. C) Keila Fernandes Batista fez uma especialização em religiões e religiosidades na UEL, e analisou o casamento sagrado sumério.

A partir de termos como "assiriologia", "Mesopotâmia” e outros correlatos, é possível encontrar na Plataforma Lattes várias referências. No entanto, os resultados apontarão para um estudante ou outro que tenha pesquisado alguma temática referente à assiriologia, mesmo que não haja mais que uma única apresentação de trabalho, e ainda no ensino médio. Alguns títulos nada têm a ver com antiguidade da Mesopotâmia, a não ser pelo fato de utilizarem esta nomenclatura para alguma finalidade. Algumas pesquisas mais aprofundadas sobre o tema, como a de Rosângela Menezes, que produziu na UFRJ uma dissertação de mestrado sobre o sítio arqueológico de Uruk, mudou a direção de suas pesquisas e atualmente trabalha com arqueologia pré-histórica no Rio de Janeiro e arte rupestre. Pesquisadores como Anisio Candido Pereira Filho, mestre em Arqueologia pela USP, que estuda cerâmica grega, interessam-se pelo universo mesopotâmico do século VII a.C., quando este estabelece contato com as peças helênicas. Ou seja, são referências que não apontam para estudiosos especialistas em assiriologia, que dedicam suas atividades acadêmicas a esta área específica. Nenhum destes, por exemplo, chegou a se tornar professor universitário concursado, e permanente, na área de História Antiga, em alguma instituição brasileira de ensino superior ou mantém projetos continuados de pesquisa e orientação sobre as culturas cuneiformes.

Após estas considerações, depois de mencionar docentes e estudantes, a maioria em atuação, é importante falar um pouco de Emanuel Bouzon, falecido em 2006. Qualquer referência à assiriologia no Brasil não seria completa sem a sua, pois foi com ele que a área ganhou seus primeiros impulsos aqui. Bouzon graduou-se em Filosofia pela PUC do Rio (1954) e em teologia pela Universidade Gregoriana de Roma (1958). Especializou-se em assiriologia e História Antiga pela Westfälische Universität Münster (1964).Fez mestrado em História Antiga Oriental pelo Pontifício Instituto Bíblico (1960), onde também concluiu seu doutoramento (1969). Vinte e quatro anos depois, ele voltou à instituição de Münster para fazer um pós-doutoramento (1988). Quem observar o Lattes 
de Bouzon (ainda disponível para consulta) poderá constatar seu interesse pelo fenômeno profético no Oriente Antigo, sobretudo em Israel. Todavia, escreveu muito sobre as culturas cuneiformes, principalmente sobre o que chamava de seus "reflexos" sobre Israel antigo. Bouzon deixou várias publicações acerca da legislação, do direito cuneiforme, da propriedade e economia na antiga Babilônia, sobre escravidão por dívida, sobre o templo e o palácio na Mesopotâmia, etc. Uma de suas maiores contribuições foi ter traduzido para o português as cartas (1986) e o "Código" de Hammurabi (2003), além de vários contratos (2000) e uma coleção de direito babilônico pré-hammurabiano (2001), facilitando o acesso das gerações futuras a estas fontes.

Bouzon também teve uma importância muito grande para Ciro Flamarion Cardoso. Os dois organizaram juntos, por exemplo, um livro, hoje clássico na historiografia brasileira, revisitando o velho conceito de modo de produção asiático (CARDOSO; BOUZON, 1990). Além disso, o assiriólogo foi membro da comissão julgadora do concurso para professor titular da Universidade Federal Fluminense prestado por Cardoso (1993). Certamente, este diálogo entre os dois serviu de inspiração e motivação para que Cardosopublicasse uma comparação sobre as religiões antigas do Egito e da Mesopotâmia (CARDOSO; BOUZON, 1999) e resenhasse uma das obras de Bouzon (CARDOSO, 2001). Outro fator importante é que Bouzon foi orientador de Marcelo Rede, quando este escreveu sua dissertação de mestrado na Universidade Federal Fluminense sobre a apropriação do universo material e o controle do espaço em Larsa, durante o período babilônico antigo. Bouzon também acompanhou a trajetória intelectual de Kátia Pozzer, que o considerava "mestre e amigo" (POZZER, 2006). Ou seja, além de ser um pilar da assiriologia brasileira, dedicando toda a sua vida a impulsionar os estudos nesta área específica da antiguidade, Bouzon ainda auxiliou na formação dos dois únicos docentes brasileiros da área de História Antiga em atividade, especialistas nesta temática. Assim, quando abordamos a assiriologia no Brasil estamos falando da continuidade do trabalho deste eminente professor e pesquisador, chamado Emanuel Bouzon, que foi buscar fora do País (principalmente na Itália e na Alemanha) os conhecimentos e habilidades necessários para possibilitar aos estudantes brasileiros uma nova vertente no que diz respeito aos estudos antigos orientais. 
No contexto atual dos estudos da história das culturas cuneiformes realizados aqui no Brasil, é notórioque, se alguém quiser ser orientado por um docente especializado na temática em alguma universidade brasileira, precisará recorrer a Katia Pozzer (UFRGS) e/ou a Marcelo Rede (USP). Assim, é possível interpretar que o cenário atual da assiriologia brasileira é desanimador; não, obviamente, pela qualidade dos docentes supramencionados, mas, em se tratando de um país de dimensões continentais, pelo fato de existirem apenas dois historiadores especialistas nesta temática. Apesar destas constatações, preferimos pensar o contexto como desafiador e repleto de oportunidades; afinal, a área de História Antiga necessita de estudantes que se dediquem a esta temática. Além disso, se, por um lado, há um quadro reduzido de professores especialistas no tema, por outro, a chamada era digital tem possibilitado novas formas de diálogo e interações que podem auxiliar na pesquisa desta temática. Assim, as informações digitalizadas e disponibilizadas por meio do open access são de importância capital para a continuidade dos estudos sobre as culturas cuneiformes no Brasil. Fazendo uso destas novas ferramentas, um estudante curioso e insistente pode solicitar ajuda virtual aos dois historiadores especialistas na área, encontrar boa parte do material já publicado em português na internet, como, por exemplo, os trabalhos de Emanuel Bouzon, e recorrer tanto à publicações feitas no exterior, como a inúmeras informações sistematizadas por sites especializados em assiriologia. É o que abordamos a seguir.

\section{De tablet para tablet - pesquisando culturas cuneiformes na web}

A partir de uma enorme gama de material disponível na rede mundial de computadores, é possível ter acesso a muita coisa sobre as culturas cuneiformes: dicionários de idiomas antigos, catálogos iconográficos, indicações bibliográficas, etc. Como temos afirmado até aqui, a era digital tem ampliado as possibilidades de discussão nesta área. Esta nova realidade tem impactado significativamente as pesquisas historiográficas em tempos de e-learning. Em diversos momentos, para o pesquisador não-especialista, é difícil distinguir a qualidade de algum material específico entre a infinidade de informações disponíveis na internet. Por isso, a seguir, apresentamos algumas alternativas para o ensino e a pesquisa das culturas cuneiformes na Web. Antes, 
todavia, de qualquer sitegrafia mais específica, e em outros idiomas, é preciso mencionar pelo menos algumas ferramentas muito importantes e mais gerais, ou seja, que servempara empreender buscas não somente sobre temáticas assiriológicas, mas também sobre várias áreas da antiguidade.

O primeiro locus virtual a ser sempre frequentado pelos interessados na temática é a própria Plataforma Lattes (lattes.cnpq.br), uma vez que o que está sendo produzido de novidade na academia brasileira em assiriologia geralmente é registrado lá. Assim, é possível encontrar tanto novos itens publicados, procurando por termos delimitados, como o nome de novos pesquisadores que surgem. Parte significativa desta pesquisa, por exemplo, só foi possível por meio desta reunião de dados. De forma conectada à Plataforma Lattes, sugerimos um acompanhamento constante a partir do GTHA (gtantiga.com). Este segundo mecanismo, embora condicione a busca a nomes previamente cadastrados, permite um acesso mais rápido, direto e facilitado aos currículos dos pesquisadores da área. Ou seja, basta abrir a página e clicar no nome dos estudiosos da área para averiguar que pesquisas estão fazendo no momento, quem estão orientando e sobre o que publicaram nos últimos meses. Também é importante ficar atento à página da SBEC (classica.org.br), pois, além dos conhecimentos sobre os estudos clássicos, vez ou outra se encontra material sobre o Oriente antigo, principalmente notícias de eventos em que a assiriologia será abordada.

Outra página que não pode ficar de fora de qualquer busca é o Academia.edu, cujo endereço já é o próprio nome. Trata-se de um website que funciona como uma rede social para acadêmicos. Foi lançado em 2008 e tem mais de oito milhões de usuários registrados em 2014. Nesta plataforma, é possível ter um perfil e especificar preferências por temas de pesquisa, além de fazer upload das publicações e ver uma análise sistemática de quem pesquisou e acessou os artigos postados, quantas pessoas leram o perfil, etc. Justamente por conta destas singularidades, o academia.edu se tornou uma boa opção para o pesquisador encontrar artigos recentes publicados na área de assiriologia por grandes nomes que trabalham com esta temática. Além disso, é possível seguir um determinado pesquisador (a) e ser avisado toda vez que este(a) disponibilizar um novo artigo. Como é possível seguir várias pessoas, pode-se estabelecer uma rede de pesquisadores de uma 
Dois portais de pesquisa, que também não podem ficar ausentes de qualquer tentativa de busca por artigos em assiriologia, são o JSTOR (jstor.org) e o Project MUSE (muse.jhu.edu). O primeiro deles foi fundado em 1995.Como o próprio nome indica (Journal Storage), é uma livraria digital que contém periódicos acadêmicos digitalizados, além de livros, documentos, resenhas, etc. No momento em que este artigo estava sendo escrito, havia 7.834 títulos registrados na categoria "History". Vários periódicos da área de assiriologia podem ser encontrados lá: Journal of the Economic and Social History of the Orient; Journal of Near Eastern Studies; Archiv für Orientforschung; Near Eastern Archaeology; Journal of Cuneiform Studies e Die Welt des Orients são alguns exemplos. $O$ mesmo vale para o segundo. Trata-se de um projeto colaborativo entre mais de 2.700 bibliotecas e editores do mundo todo, que existe desde 1993, a partir da Johns Hopkins University Press e que, desde 2012, oferece várias opções de busca. Há inúmeras referências na área de assiriologia. Ambos, tanto o JSTOR quanto o Project MUSE podem ser acessados a partir do Portal da Pesquisa (portaldapesquisa.com.br). Claro que há inúmeras ferramentas de busca mais gerais; no entanto, é preciso avançar até as específicas.

Começamos com a página do Laboratório do Antigo Oriente-Próximo (Laop), da Universidade de São Paulo (FFLCH). Trata-se de um núcleo que reúne especialistas de várias áreas, que estudam temas diversificados, abrangendo as sociedades do Egito, da Anatólia, da Síria, Palestina e, claro, Mesopotâmia. O Laop é coordenado por Marcelo Rede, historiador já mencionado no início deste artigo, e tem como membro de seu conselho deliberativo Carlos Henrique Barbosa Gonçalves, pesquisador dos saberes matemáticos na Mesopotâmia, também já apresentado. Dentre os colaboradores internacionais do laboratório, estão Philipe Clancier, Jacob Dahl, Cécile e Dominique Charpin, por exemplo, grandes nomes da assiriologia. Alguns links da página ainda estão em desenvolvimento e o próprio grupo, em constante formação, mas é possível ver que o Laop, em parceria com a Editora Targumim e a equipe do Histoire et Archéologie de 
L’Orient Cunéiforme (Haroc), publicou a obra "Escritas Cuneiformes - História, usos e deciframentos". Ou seja, trata-se de um página para acompanhar de perto.

Figura 1: Página principal do LAOP

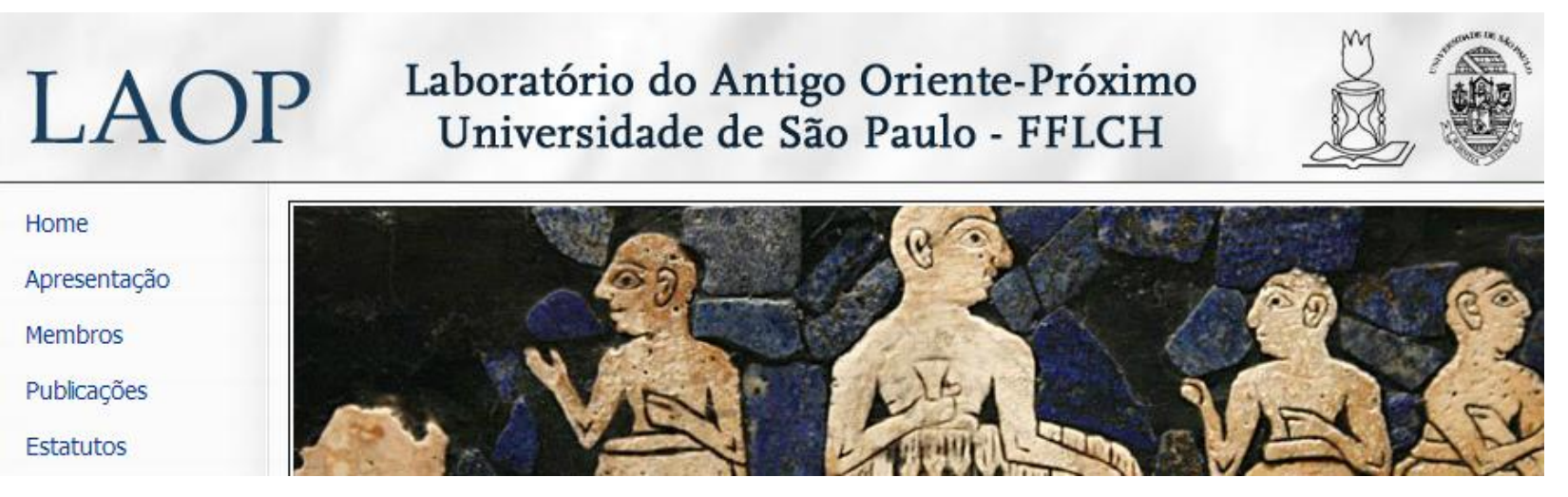

Fonte: LAOP, 2014. Ver referência

Outro laboratório brasileiro muito importante por contribuir na formação de vários dos estudantes mencionados neste artigo é o Laboratório de Pesquisa do Mundo Antigo (Lapema), criado pela historiadora Kátia Pozzer, quando lecionava na Ulbra de Canoas-Rs. Foi constituído em 2007, graças a recursos financeiros obtidos a partir da aprovação no CNPQ dentro do projeto de pesquisa "A representação da Guerra na Iconografia Neo-Assíria", temática que tem representado o núcleo da maior parte das pesquisas ali realizadas. O Lapema, segundo informações disponibilizadas em sua própria página, "tem, entre seus objetivos, o intuito de contribuir para o desenvolvimento, ampliação e divulgação da área de estudos interdisciplinares sobre Antiguidade no Brasil, bem como associar-se a grupos de pesquisa no exterior". Decorridos já alguns anos de sua criação, de fato estes objetivos parecem alcançados. O Lapema contribuiu significativamente, a partir de vínculos com a linha de pesquisa "Memória e Preservação de bens Culturais" do grupo de pesquisa “Patrimônio Cultural e Identidades", certificado pela Ulbra e o CNPQ, para o desenvolvimento de estudos que ultrapassam inclusive a área de História Antiga. Ele foi a base de sustentação para a aprovação de vários projetos de iniciação científica, a publicação de artigos e livros na área da assiriologia. Assim, 
mesmo que mude o foco de estudo, os interessados no tema devem consultar os trabalhos já nele realizados, uma vez que o laboratório tem espaço garantido na história da assiriologia no Brasil.

Figura 2: Página principal do Lapema

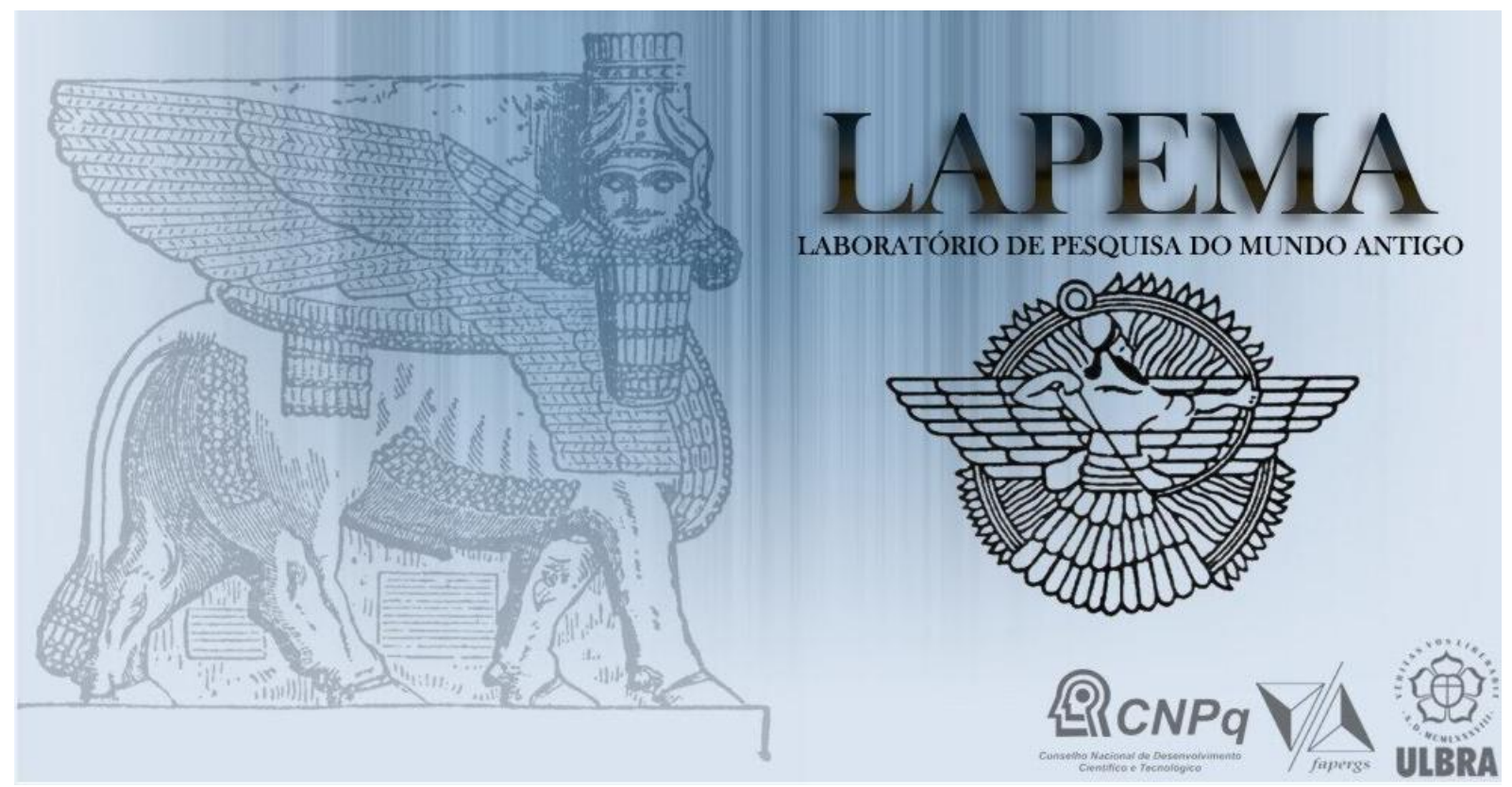

Fonte: LAPEMA, 2014. Ver referência.

Estes têm sido os dois grandes incentivadores virtuais das pesquisas em assiriologia realizadas no Brasil. Na Argentina, há o Centro de Estudios de Historia Del Antiguo Oriente (Cehao) (uca.edu.ar/cehao), da Pontificia Universidad Católica Argentina. Trata-se de um centro universitário de investigação fundado em 2002 e que tem como objetivo principal a investigação no campo da História e da Arqueologia do Oriente Antigo. O centro administra várias publicações de livros, artigos, boletins de divulgação, além de promover diversas atividades, como exposições, congressos, jornadas e seminários. Dentre as preocupações do Cehao está a assiriologia e há, entre seus membros, especialistas no tema, como, por exemplo, a profa. Romina Della Casa, que estuda hititas. Em sua página na internet, o Cehao também disponibiliza uma série de links para outros espaços virtuais importantes dedicados ao Oriente Antigo. 
Figura 3: Página principal do Cehao
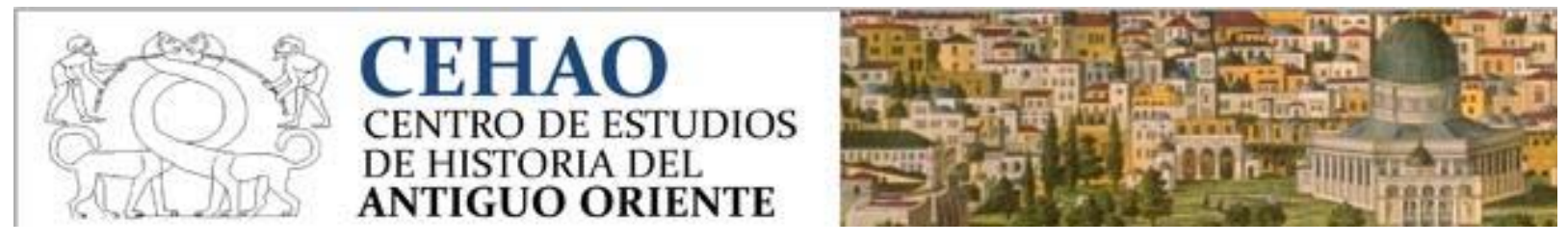

Fonte: CEHAO, 2014. Ver referência.

Em outros idiomas, principalmente em inglês, temos uma variação enorme de possibilidades. Há uma série de páginas contendo desde conjugadores de verbos da língua acádica, como o Akkadian Parser (wiglaf.org/akkadian/parserf.html); dicionários de língua acádica, tais como o disponibilizado pelo Trinity College Cambridge, que contém ainda uma bibliografia de suporte à pesquisa (trin.cam.ac.uk/cda_archive/default.htm); lista de signos da escrita acádica (alain.be/akkadien.html); projetos como o The Babylonian Nineveh Texts, parte do Ashurbanipal Library Project of the British Museum, dirigido por J. C. Fincke, Universität Heidelberg, que disponibilizou online textos babilônicos da cidade de Nínive oriundos da biblioteca do rei assírio Ashurbanipal (668627 a.C.) e conservados no British Museum (rzuser.uniheidelberg.de/ n53/nineveh/index.htm), até fontes que, uma vez instaladas, permitem escrever idiomas que utilizaram o sistema de escrita cuneiforme no computador, readaptando scripts produzidos milênios atrás para o nosso tempo, tais como o Unicode Fonts for Ancient Scripts (users.teilar.gr/ g1951d/), o Unicode Cuneiform Fonts (hethport.uni-wuerzburg.de/cuneifont/) e o Cuneiform fonts for TeX/LaTeX/PDFLaTeX (www-hep2.fzu.cz/ piska/cuneiform.html). No entanto, por questões de delimitação, apresentamos a seguir apenas algumas das principais páginas, dando preferência às mais gerais, que abrangem mais conteúdos de assiriologia, interdisciplinares, de navegação mais facilitada e objetiva para os iniciantes na área, e que contêm a maior quantidade de links para outros projetos e páginas, o que certamente ampliará o leque de pesquisa.

Sem dúvida, um projeto que não pode deixar de integrar uma sitegrafia como a pretendida neste artigo, e de forma alguma pode deixar de ser visitado, é o Knowledge and Power in the Neo-Assyrian Empire, dirigido por pesquisadores da Universidade de 
Cambridge, da University College London e da University of Pennsylvania, que contam com suporte material de acadêmicos de inúmeras universidades do mundo inteiro. O website deste projeto disponibilizou na internet, de forma gratuita, a partir de uma colaboração com um projeto anterior, intitulado Neo-Assyrian Text Corpus Project, nada mais nada menos que 2.100 traduções e transliterações de textos antigos da região que nos acostumamos a chamar de Mesopotâmia. Além destas referências, há ainda uma grande quantidade de textos advindos de palestras e seminários de importantes estudiosos do tema, além de indicações bibliográficas e outros materiais fundamentais para a assiriologia (oracc.museum.upenn.edu/saao/knpp/).

Figura 4: Página principal do Knowledge and Power in the Neo-Assyrian Empire

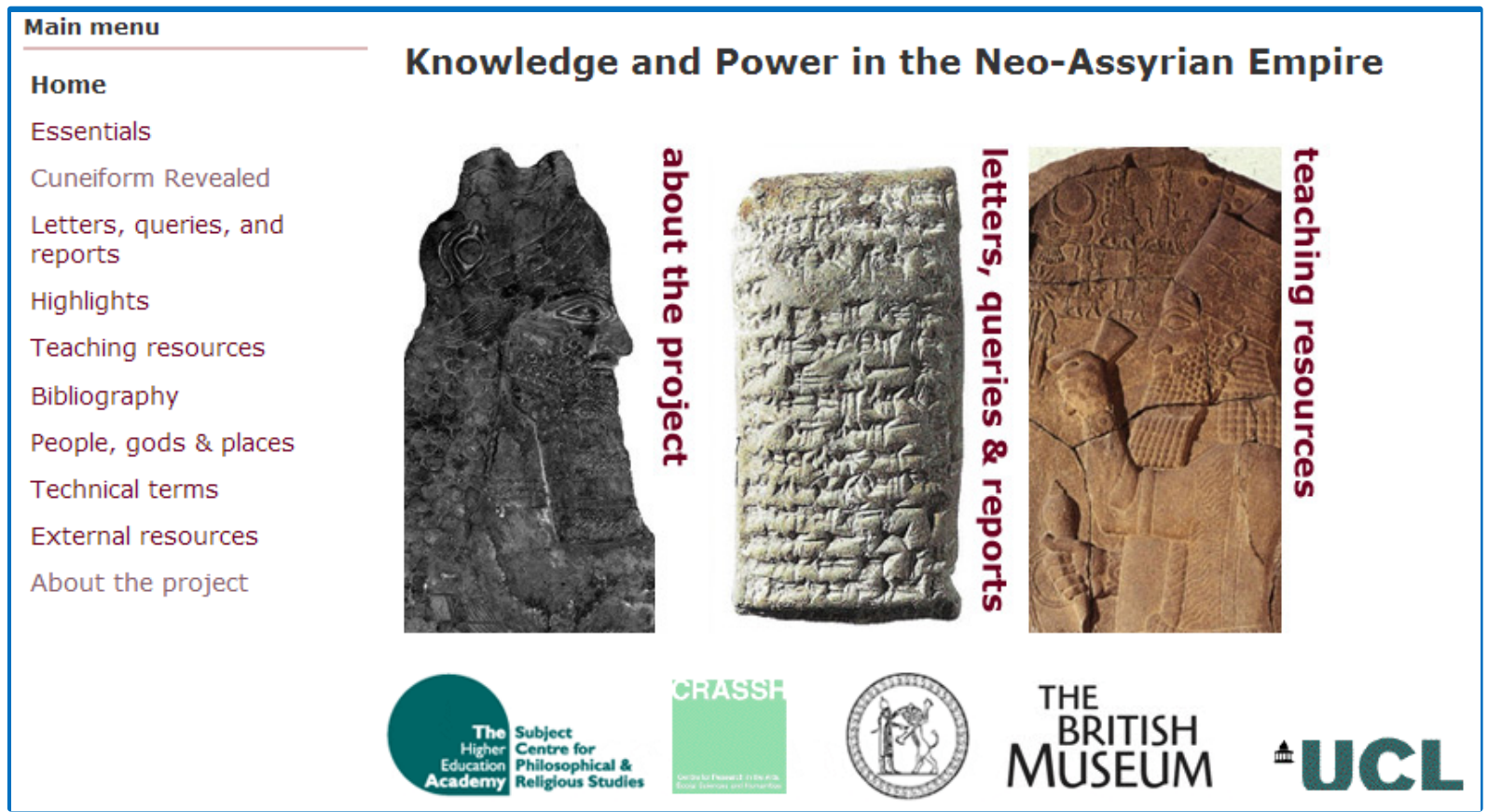

Fonte: Knowledge and Power in the Neo-Assyrian Empire, 2014. Ver referência.

O The Melammu Project - The Heritage of Mesopotamia and the Ancient Near East, projeto que surgiu a partir de Helsinki, na Finlândia, no ano 2000, é mais um organizado de forma coletiva por uma série de pesquisadores de várias universidades do mundo. Ele investigou a continuidade, a transformação e difusão das culturas da Mesopotâmia e do 
Oriente Próximo do terceiro milênio a.C. até o período islâmico. Disponibiliza, periodicamente, de forma gratuita, na rede mundial de computadores, sustentando a ideia de oppen acces, vários arquivos interessantes para os estudiosos das culturas cuneiformes, que vão desde textos mais simples, de caráter introdutório, até debates mais complexos, em vários idiomas, sobre inúmeros assuntos da área, alguns, inclusive, de temas atuais. Boa parte do material provém dossymposia que promovem o intercâmbio de ideias entre estes especialistas de diferentes áreas do saber (arqueologia, história, literatura, antropologia, etc.), o que permite reunir contribuições mais sistemáticas e interdisciplinares sobre o tema. Assim, dentro desta perspectiva, a página do The Melammu Project apresenta uma vasta biblioteca de textos historiográficos da área de assiriologia em PDF, além de referências a uma série de evidências textuais, artísticas, arqueológicas, etnográficas e linguísticas para o estudo da Mesopotâmia e do Oriente Antigo. (aakkl.helsinki.fi/melammu/).

Figura 5: Página principal do Melammu Project

\section{Welcome to the Website of the Melammu Project}

The Heritage of Mesopotamia and the Ancient Near East
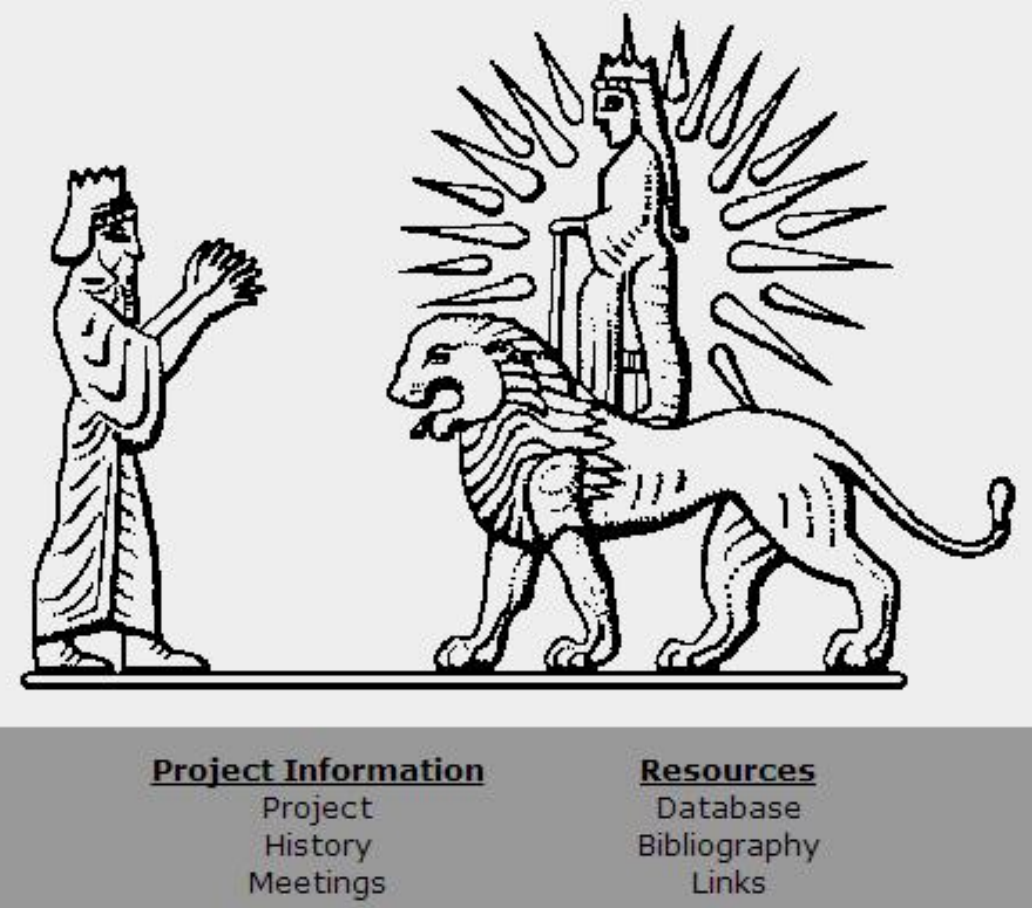

Fonte: The Melammu Project, 2014. Ver referência. 
Também é importante mencionar o projeto do professor de assiriologia Niek Veldhuis, do Departament of Near Eastern Studies da University of California, Berkeley. Trata-se do Digital Corpus of Cuneiform Lexical Texts (DCCLT), cujo objetivo é publicar na Web todas as listas lexicográficas da Mesopotâmia, algo que pode ser comparado aos nossos modernos dicionários e desempenhava função angular na educação dos escribas e na vida intelectual deste período da história da humanidade. Estas listas surgiram com a invenção da escrita (cerca de 3000 a.C.) e continuaram em utilização enquanto durou a prática de escrita cuneiforme, segundo as explicações do próprio Veldhuis na página do projeto (nes.berkeley.edu/Web_Veldhuis/research.html).

Figura 6: Página principal do dcclt

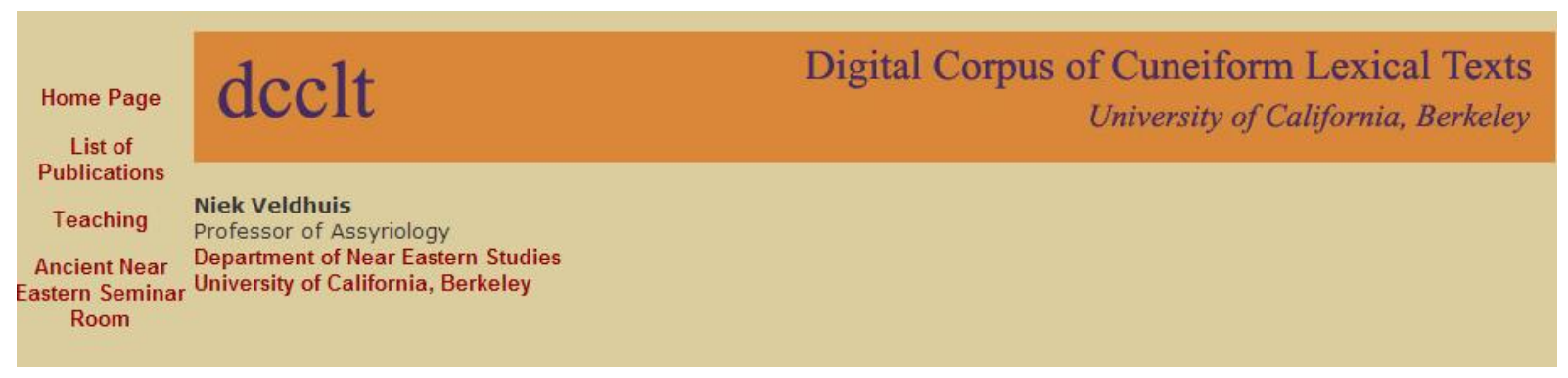

Fonte: DCCLT, 2014. Ver referência.

Outro aparato que pode auxiliar na pesquisa das culturas cuneiformes é o The Eletronic Text Corpus of Sumerian Literature (ETCSL), um projeto da Faculty of Oriental Studies da University of Oxford. O sumério é a primeira língua da qual temos evidências escritas e uma atividade literária. Neste projeto, em particular, são sistematizadas cerca de 400 composições literárias da Mesopotâmia. Os textos estão disponíveis tanto em sumério, de forma transliterada, como em inglês, acompanhados de bibliografia específica acerca de cada um deles (etcsl.orinst.ox.ac.uk/). 


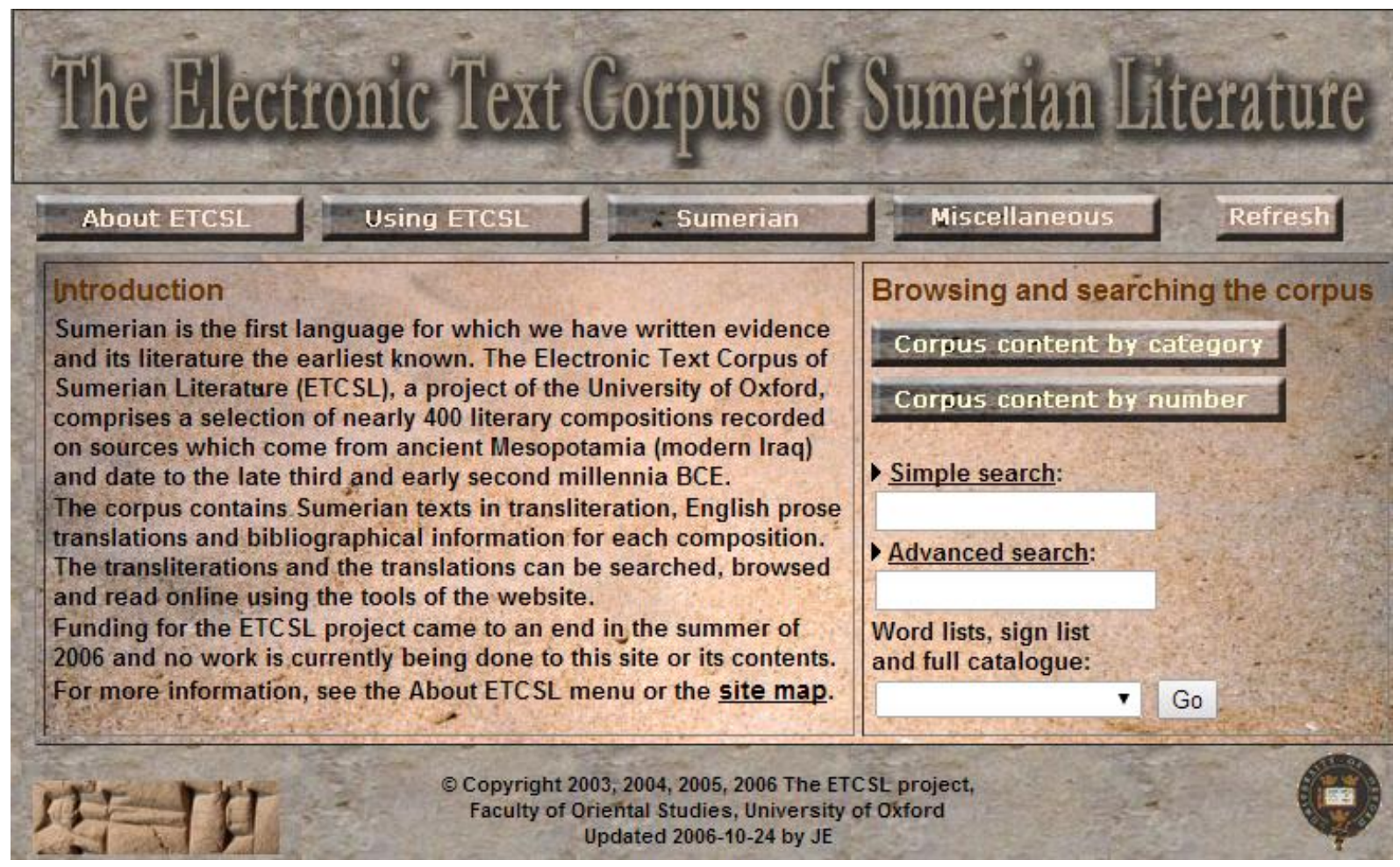

Fonte: ETCSL, 2014. Ver referência.

Lançado em 2001, o Eletronic Tools and Ancient Near East Archives (Etana) também é um projeto colaborativo e multi-institucional que fornece suporte para o estudo da história e da cultura do Antigo Oriente Próximo. O Etana disponibiliza 367 itens importantes, não mais cobertos por copyright ou com permissão de quem detém o direito sobre eles, para o ensino e a pesquisa assiriológica, a maior parte disponível a partir da ferramenta Google Books (etana.org). Além disso, a página tem ainda um link para o ABZU, disponível desde 5 de outubro de 1994, projeto editado com apoio financeiro da Andrew W. Mellon Foundation, por Charles E. Jones, bibliotecário chefe do Institute for the Study of the Ancient World da New York University, um guia para acessar várias publicações relevantes da área. As referências estão em ordem alfabética, sistematizadas pelos nomes dos autores, e ultrapassam duas mil. 

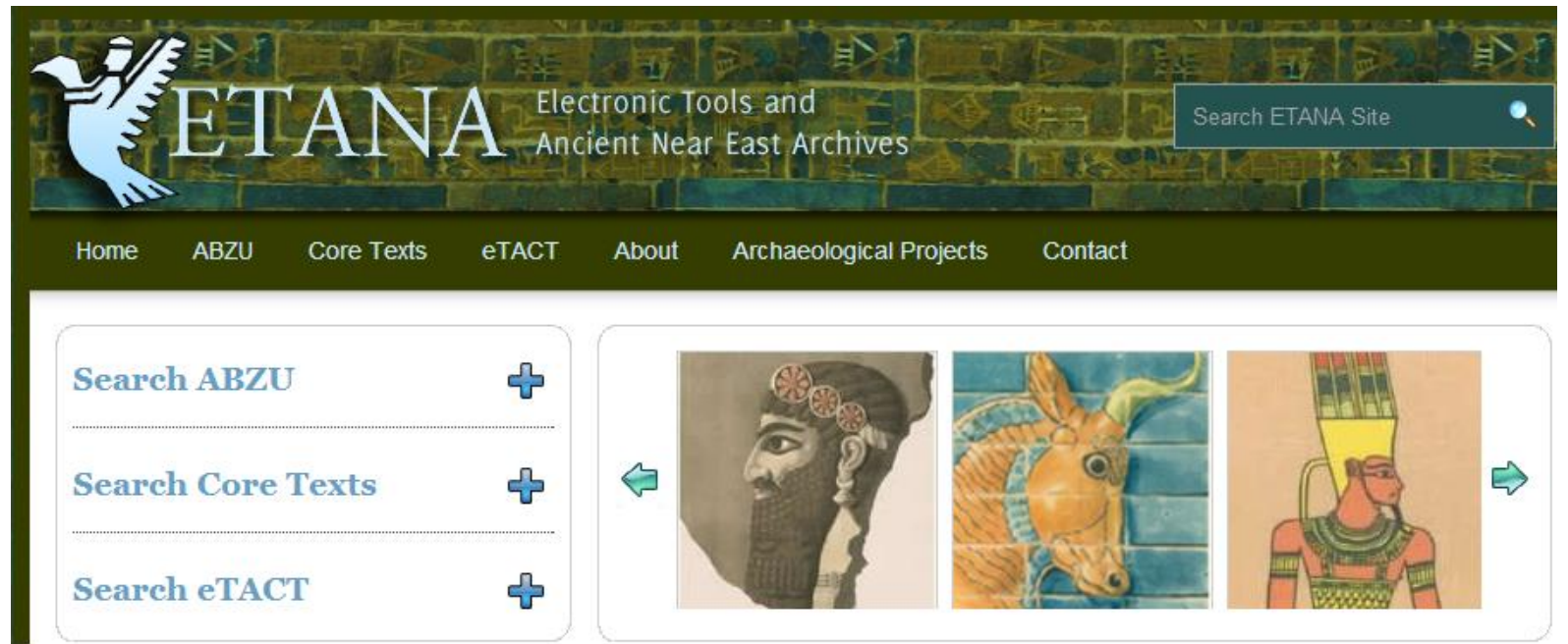

Fonte: ETANA, 2014. Ver referência.

Talvez a mais importante e completa ferramenta virtual para a pesquisa em assiriologia seja a The Cuneiform Digital Library Initiative (CDLI). O projeto, dirigido de forma conjunta por Robert K. Englund, da University of California, de Los Angeles, e Jürgen Renn, do Max Planck Institute for the History of Science, de Berlim, representa os esforços de um grupo internacional de assiriologistas, curadores de museus e historiadores da ciência para disponibilizar na internet as fontes escritas em tablets cuneiformes (http://cdli.ucla.edu/). O período histórico coberto pelo projeto se extende de 3350 a.C. até o fim da era pré-cristã. Segundo as próprias informações da página, os documentos, mantidos sob domínio público e privado, podem ser estimados em mais de meio milhão de exemplares. Destes, o projeto catalogou mais de 290.000 , oferecendo textos, imagens, transliterações, glossários, fontes digilitalizadas e foto-arquivos de cuneiformes, além de uma lista dos principais museus com peças de interesse da assiriologia. Também hálinks para várias obras, inclusive uma espécie de wikipédia própria, a CDLI WIKI, especializada nos termos importantes para os estudos das culturas cuneiformes, desenvolvida em parceria com a University of Oxford, que contém, além das entradas para os termos, uma List of Abbreviations for Assyriology, com todas as abreviações importantes que um especialista na área deve conhecer. A página também apresenta outra lista, intitulada Recent publications in Assiriology, que fornece indicações 
do que de mais atual vem sendo produzido na área, e fornece quase uma centena de obras publicadas entre 2008 e 2014 sobre as culturas cuneiformes. Há também uma Bibliography of Sumerian Literature, com cerca de 1.000 referências (cdli.ox.ac.uk/wiki/), algo bastante sintomático, principalmente considerando que no Brasil ainda é possível ouvir alguns professores, até mesmo da área de História Antiga, alegando dificuldade, ou mesmo impossibilidade, no estudo dessas culturas devido à falta de fontes e de bibliografia especializada.

Figura 9: Página principal da CDLI
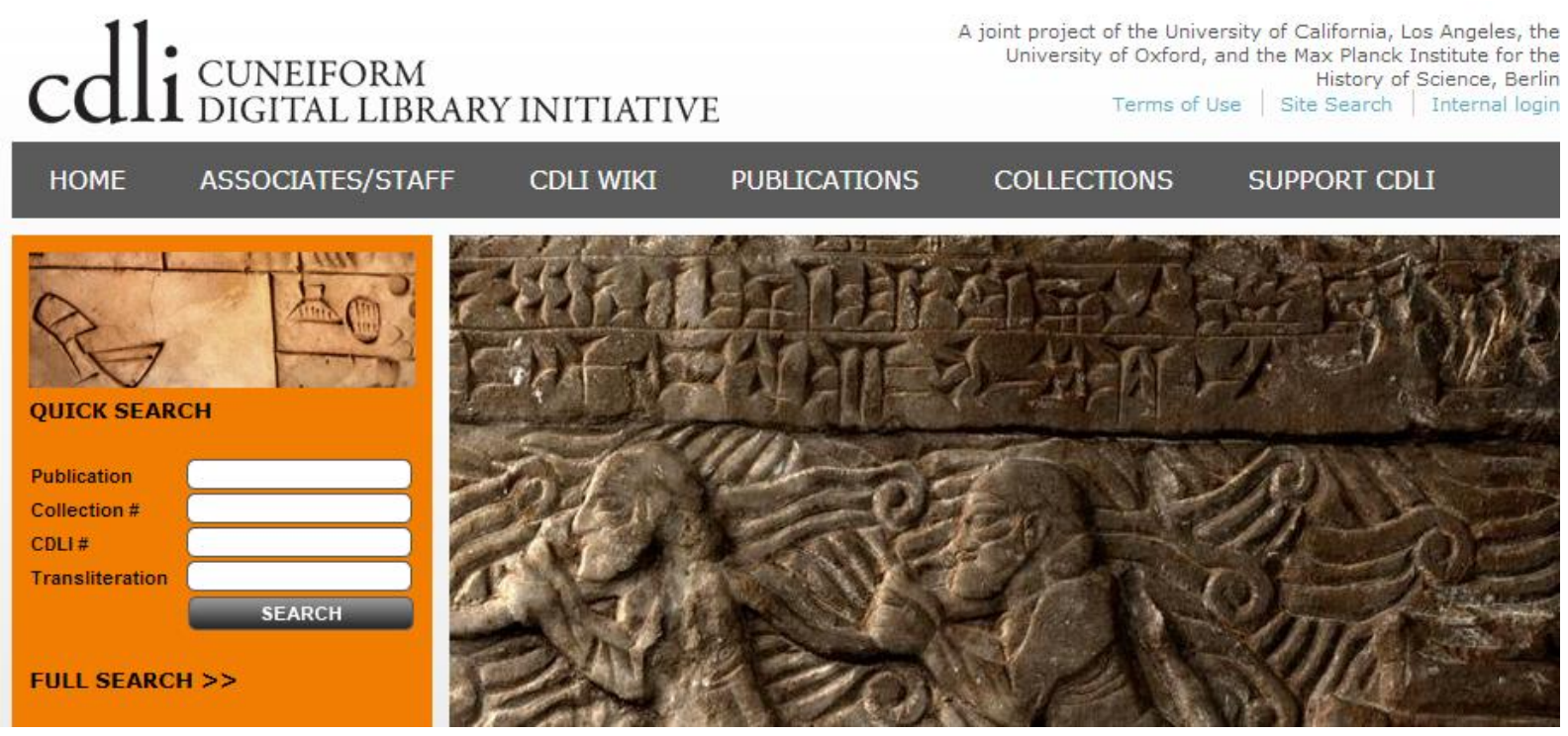

Fonte: CDLI, 2014. Ver referência.

Além destas ferramentas, o Materialities of Assyrian Knowledge, por exemplo, em funcionamento de 2013 a 2014, oferece a oportunidade de acompanhamento do caminho de tablets e outros artefatos da antiga cidade assíria de Kalhu até seus destinos nas coleções dos museus contemporâneos e também como são postados na internet (oracc.museum.upenn.edu/nimrud/abouttheproject/index.html). A parte de Mesopotâmia do Livius também contém várias referências ao tema e é sempre muito importante (livius.org). O projeto Ancient Mesopotamian Gods and Goddesses apresenta uma relação sistemática das divindades da Mesopotâmia antiga 
(http://oracc.museum.upenn.edu/amgg/abouttheproject/). Há também vários exemplos de organizações, associações de estudo, institutos de pesquisa e sociedades dedicadas à assoriologia, como aAmerican Oriental Society (umich.edu/ aos/), o Oriental Institute of the University of Chicago (oi.uchicago.edu/research/info/) e o Deutsche Orient-Gesellschaft (orient-gesellschaft.de/), que fornecem, em suas páginas, material de apoio. 0 Departament of The Languages and Cultures of The Near and Middle East da School of Oriental Studies, da University of London gravou alguns de seus especialistas lendo fontes históricas da Mesopotâmia antiga. Assim, é possível escutar, por exemplo, a leitura do hino a Ishtar, na voz de Karl Hecker e Doris Prechel; do "Código" de Hammurabi, na de Albert Naccache e Aage Westenholz e vários outros textos, como a Epopeia de Gilgamesh, em mais de uma versão (http://www.soas.ac.uk/baplar/recordings/). Os principais museus do mundo também disponibilizam coleções de artefatos relacionados com assiriologia, possibilitando a sua pesquisa virtual, casos do British Museum (britishmuseum.org), onde o visitante encontra os relevos do Palácio de Nínive; do Louvre (http://www.louvre.fr/), que possui o famoso "Código" de Hammurabi; e do Pergamom (smb.museum), que tem em sua coleção o portal de Ishtar. Ou seja, há vários mecanismos que podem auxiliar os interessados em nossa temática.

Uma relação mais detalhada certamente faria este artigo ultrapassar o limite de páginas permitido; no entanto, acreditamos que o leitor já tenha compreendido nosso intuito, que foi o de mostrar serem várias as possibilidades que se abrem à pesquisa assiriológica na era digital. Há fontes disponíveis; há historiografia especializada na temática, e a internet é sem dúvida é uma facilitadora.

\section{Considerações finais}

O sistema cuneiforme funcionava como um script. Nele poderiam ser escritos vários idiomas. É interessante considerar que continuamos a utilizar scripts. Foi a partir de uma linguagem assim que as páginas nas quais o leitor navegou para ler este artigo foram criadas. De igual modo, também é curioso pensar no fato de que, há milhares de anos, na Mesopotâmia, jovens aprendizes da arte de escrever seguravam um tablet em uma de 
suas mãos e escolhiam inserir nele vários símbolos dentre as possibilidades de determinado idioma. Os tablets agora são outros, com novas ferramentas, criando outras interações. Os significados são diferentes. No entanto, mesmo após tanto tempo, em diversas partes do mundo, seres humanos continuam utilizando tablets para produzir conhecimento e sociabilidades. Pensando nestes termos, podemos ver que a assiriologia não é um corpo estranho na chamada era digital.

Figura 10: Acima: Matthew Stolper, professor do Oriental Institute, University of Chicago, examina um tablet Persa (esq) e o acadêmico Jeffrey Szuchman estuda a versão digital de um tablet da Babilônia (dir). Abaixo: ressignifcações a partir de modelos de tablets cuneiformes para capas de Iphone (esq.) e acadêmico tentando formar seus primeiros sinais cuneiformes em oficina do Laboratório Blumenauense de Estudos Antigos e Medievais da FURB (dir).

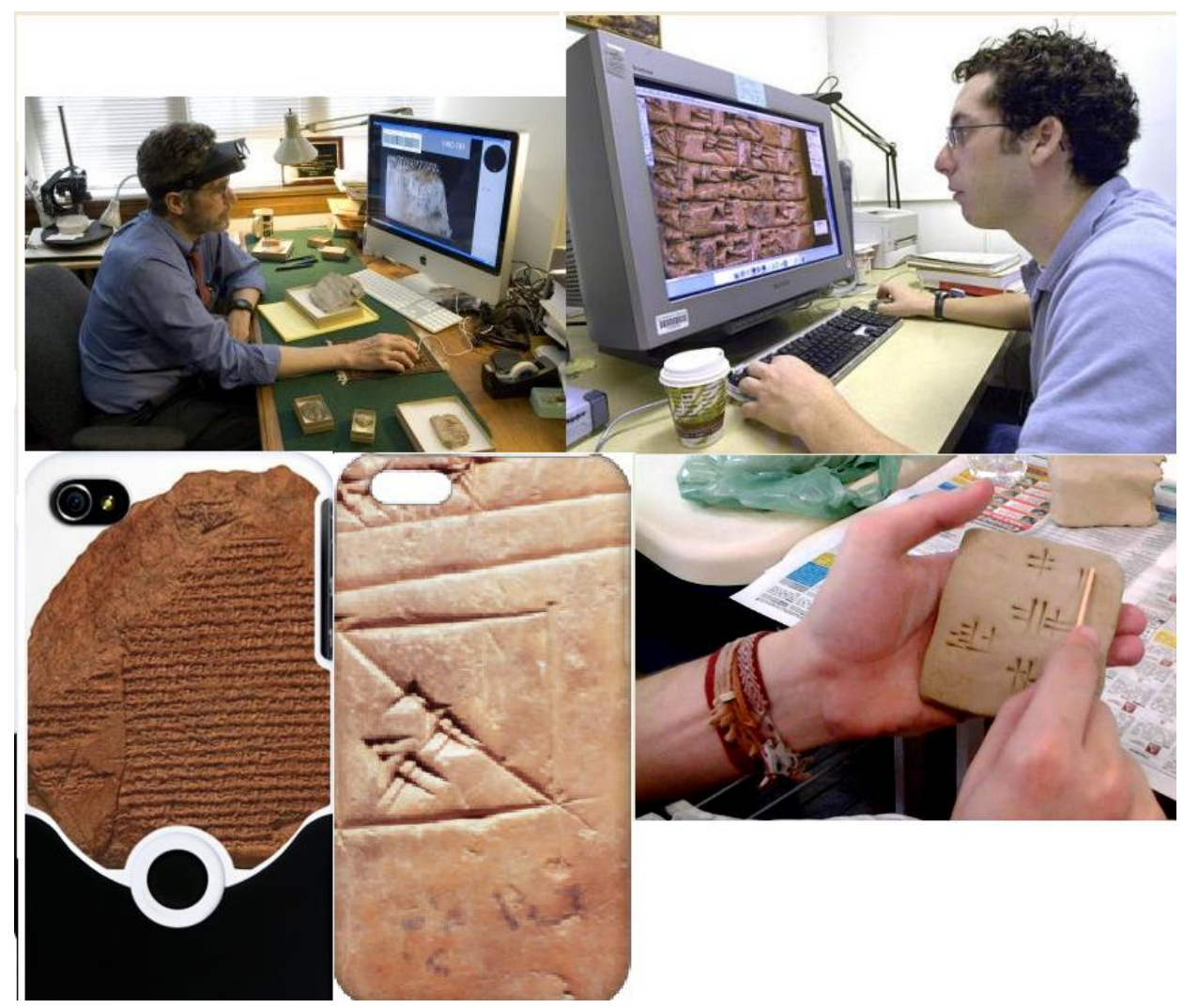

Créditos: Respectivamente, University of Chicago, University of California, Bigstock Iphone cases, Universidade de Blumenau.

Vimos que a internet transformou a pesquisa assiriológica, o que fez aumentar significativamente as possibilidades de diálogo e de interação, permitindo ao público brasileiro ter open access a uma infinidade de material específico e entrar em contato com 
as principais publicações da área. Não mais se sustentam justificativas como a ausência de fontes e de bibliografia especializada para que estudos, pesquisas e orientações que tenham como objeto as culturas cuneiformes deixem de ser conduzidas. Vimos que há disponível na rede mundial de computadores muita coisa sobre tais culturas: dicionários de idiomas antigos, catálogos iconográficos, indicações bibliográficas, etc. Ou seja, milhares e milhares de referências.

Também foi possível observar que a área de História Antiga no Brasil cresceu bastante nas últimas décadas; poderíamos dizer, em progressão geométrica. Apesar disso, a assiriologia não acompanhou este desenvolvimento, pois, enquanto $74 \%$ dos professores que ministram a disciplina de História Antiga de forma permanente em alguma instituição de ensino superior no Brasil estudam Grécia e Roma, apenas 2,17\% são assiriólogos. Alguns docentes parecem ignorar a presença tanto do Egito quanto da Mesopotâmia como parte fundamental da disciplina a que chamamos de História Antiga. Descumprindo o que está previsto nas próprias ementas das instituições em que lecionam, muitas vezes decidem por conta própria possibilitar aos acadêmicos de graduação oferecer conteúdos relacionados apenas com Grécia ou Roma. A continuidade dos estudos em Antiguidade Oriental no Brasil também depende de incentivo, que, se ausente, pode fazer com que nossa área perca incontáveis talentos. Assim, os estudos em assiriologia precisam ser mais encorajados no Brasil pelos próprios professores de História Antiga; afinal, a área não pode se limitar apenas à Grécia Antiga ou a Roma, ainda mais considerando estas possibilidades da era digital. Esperamos que este artigo tenha chamado a atenção para estas questões. 


\section{Referências}

\section{A) Obras Gerais}

BOUZON, E. As Cartas de Hammurabi. 1. ed. Petropolis: Vozes, 1986. 240 p.

BOUZON, E.. Contratos pre-hammurabianos do reino de Larsa. 1. ed. Porto Alegre: Edipucrs, 2000. v. 1. 391p.

BOUZON, E..O Código de Hammurabi. 10. ed. Petrópolis: Vozes, 2003. 238 p.

BOUZON, E.. Uma coleção de direito babilônico pré-hammurabiano: leis do reino de Esnunna. 1. ed. Petrópolis: Editora Vozes, 2001. v. 1, 207 p.

CAMPOS, Carlos Eduardo da Costa. Repensando a história antiga: debates e questionamentos. In: Eliana Silveira; Margaret Bakos. (Org.). vida, cotidiano e morte. 1. ed. Porto Alegre: Letra \& Vida, v. 1, 2012. p. 13-18.

CANDIDO, Maria Regina. A pesquisa de Antiguidade Clássica no Brasil. In: ZIERER, Adriana; XIMENDES, Carlos Alberto. História antiga e medieval: cultura e ensino. São Luís: Editora UEMA, 2009.

CARDOSO, Ciro Flamarion. Uma coleção de direito pré-hammurabiano: leis do reino de Eshnunna, de Emanuel Bouzon (resenha). Atualidade teológica. Rio de Janeiro: PUCRJ, v. 5, p. 249-250, 2001.

CARDOSO, Ciro Flamarion. Bouzon, M. (Org.). O modo de produção asiático:nova visita a um velho conceito. Rio de Janeiro: Campus, 1991.

CARDOSO, Ciro Flamarion; Bouzon, M. (Org.).. Deuses, múmias e ziggurats: uma comparação das religiões antigas do Egito e da Mesopotâmia. Porto Alegre: Editora Pontifícia Universidade Católica do Rio Grande do Sul, 1999.

CARDOSO, Ciro Flamarion; Bouzon, M. (Org.). Modo de produção asiático: nova visita a um velho conceito. Rio de Janeiro: Campus, 1990. 137 p.

CARVALHO, Maria Margarida; FUNARI, Pedro. Paulo. Os avanços da história antiga no Brasil: algumas ponderações. História, v. 26, n. 1, p.00-00, 2007.

CERQUEIRA, Fábio Vergara. De Ur a Atenas: difusão de tradições musicais e organológicas. In: POZZER, Katia Maria Paim; SILVA, Maria Aprecida Oliveira; PORTO, Vagner Cavalheiro. (Org.). Um outro mundo antigo. 1. ed.São Paulo: Editora Annablume, v. $1,2013$. 
DAINTITH, John; WRIGHT, Edmund. A Dictionary of computing. 6. ed.. Oxford: Oxford University Press, 2008.

DANIEL, Dominique. Teaching students how to research the past: historians and librarians in the digital age. The History Teacher, v. 45, n. 2, p.00-00, 2012.

DARNTON, Robert. A questão dos livros: passado, presente e futuro. Local : Companhia das Letras, 2010.

FAVERSANI, Fábio.; CAMPOS, Carlos Eduardo da Costa . Prof. Fábio Faversani ressalta o crescimento dos estudos da antiguidade no Brasil. Rio de Janeiro: UERJ, 2009 (Entrevista). Philía - Jornal Informativo de História Antiga, ano XII, n. 32., nov./dez., p.oo00, 2009.

FUNARI, Pedro Paulo. Apresentação. In: FUNARI, Pedro Paulo Abreu (Org.). Repensando o mundo antigo. Campinas: IFCH/UNICAMP, 2005. Col. Textos Didáticos, n. 47.

GARRAFFONI, Renata Sena.; FUNARI, Pedro Paulo Considerações sobre o estudo da Antiguidade Clássica no Brasil. Acta Scientiarum: Education. v. 32, n. 1, p. 1-6, 2010.

LUCCHESI, Anita. História e historiografia digital: diálogos possíveis em uma nova esfera pública. In: SIMPÓSIO NACIONAL DE HISTÓRIA: CONHECIMENTO HISTÓRICO E DIÁLOGO SOCIAL, XXVII, Natal, 2013.. Anais.... Natal: ANPUH,2013. v. 1. p. 1-17,

LUCCHESI, Anita. .Sopravviverà la storia all'ipertesto? Qualche spunto sulla scrittura della storia ai tempi di internet. Diacronie: studi di storia contemporanea, v. 12, p. 1-18, 2012.

MARQUES, Juliana Bastos. Trabalhando com a história romana na Wikipédia: uma experiência em conhecimento colaborativo na universidade. Revista História Hoje, v. 2, p. 329-346, 2013.

POZZER, Kátia Maria Paim. Réquiem para Emanuel Bouzon. Phoinix. Rio de Janeiro: UFRJ, v. 12, p. 295-297, 2006.

SANTOS, Dominique; CONTADOR, Ana Letícia; CRESCENCIO, Aniele Almeida. Representações do espaço da cidade na epopeia de gilgamesh: a Uruk das grandes muralhas. Revista Sapiência, v. 1, p. 115-129, 2012.

SAWAYA, Márcia Regina. Dicionário de informática e internet. São Paulo: Nobel, 1999. 
SILVA, Glaydson José da. Os avanços da história antiga no Brasil. In: SIMPÓSIO NACIONAL DE HISTÓRIA: ANPUH 50 anos, XXVI, , julho de 2011.: Anais.., São Paulo: ANPUH< 2011.

SILVA, Semíramis Corsi. Aspectos do ensino de história antiga no Brasil: algumas observações. Alétheia: Revista de Estudos sobre Antiguidade e Medievo, v. 1, p.00-00, 2010.

TAVARES, Célia Cristina da Silva. História e informática. In: CARDOSO, Ciro Flamarion, VAINFAS, Ronaldo (Orgs.). Novos domínios da história. Rio de Janeiro, Elsevier, 2012.

\section{B) Sitegrafia}

LAOP - Laboratório do Antigo Oriente-Próximo [Site na Internet]. São Paulo: USP/FFLCH, 2014. Disponivel em < http://laop.vitis.uspnet.usp.br/>. Acesso em 02 de julho de 2014.

LAPEMA - Laboratório de Pesquisa do Mundo Antigo [Site na Internet]. CANOAS: ULBRA, 2014. Disponivel em < http://lapema.blogspot.com.br/>. Acesso em 02 de julho de 2014.

CEHAO - Centro de Estudios de Historia Del Antiguo Oriente [Site na Internet]. BUENOS AIRES: UCA, 2014. Disponivel em < uca.edu.ar/cehao >. Acesso em 02 de julho de 2014.

KNOWLEDGE AND POWER IN THE NEO-ASSYRIAN EMPIRE [Site na Internet]. CAMBRIDGE; UCL; UNIVERSITY OF PENNSYLVANIA, 2014. Disponivel em < oracc.museum.upenn.edu/saao/knpp/ >. Acesso em 02 de julho de 2014.

THE MELAMMU PROJECT, 2014. [Site na Internet]. HELSINKI, 2014. Disponivel em < Link: aakkl.helsinki.fi/melammu/>. Acesso em 02 de julho de 2014.

DCCLT - Digital Corpus of Cuneiform Lexical Texts [Site na Internet]. BERKELEY, 2014. Disponivel em < nes.berkeley.edu/Web_Veldhuis/research.html>. Acesso em 02 de julho de 2014.

ETCSL - The Eletronic Text Corpus of Sumerian Literature [Site na Internet]. OXFORD, 2014. 2014. Disponivel em < etcsl.orinst.ox.ac.uk/>. Acesso em 02 de julho de 2014.

ETANA - Eletronic Tools and Ancient Near East Archives [Site na Internet]. NEW YORK, 2014. Disponivel em < etana.org >. Acesso em 02 de julho de 2014.

CDLI - The Cuneiform Digital Library Initiative, 2014. [Site na Internet]. CALIFORNIA, UCLA, 2014. Disponivel em < http://cdli.ucla.edu/ >. Acesso em 02 de julho de 2014. 
Recebido em 31/03/2014 Aprovado em 27/06/2014

Universidade do Estado de Santa Catarina - UDESC

Programa de Pós-Graduação em História - PPGH

Revista Tempo e Argumento

Volume 06 - Número 12 - Ano 2014 tempoeargumento@gmail.com 